\title{
MuNDOS DO TRABALHO
}

Publicação eletrônica semestral do GT “Mundos do Trabalho” - ANPUH

\section{Dossiê \\ E. P. Thompson}

\section{Organização \\ Marcelo Badaró Mattos Vinícius de Rezende}

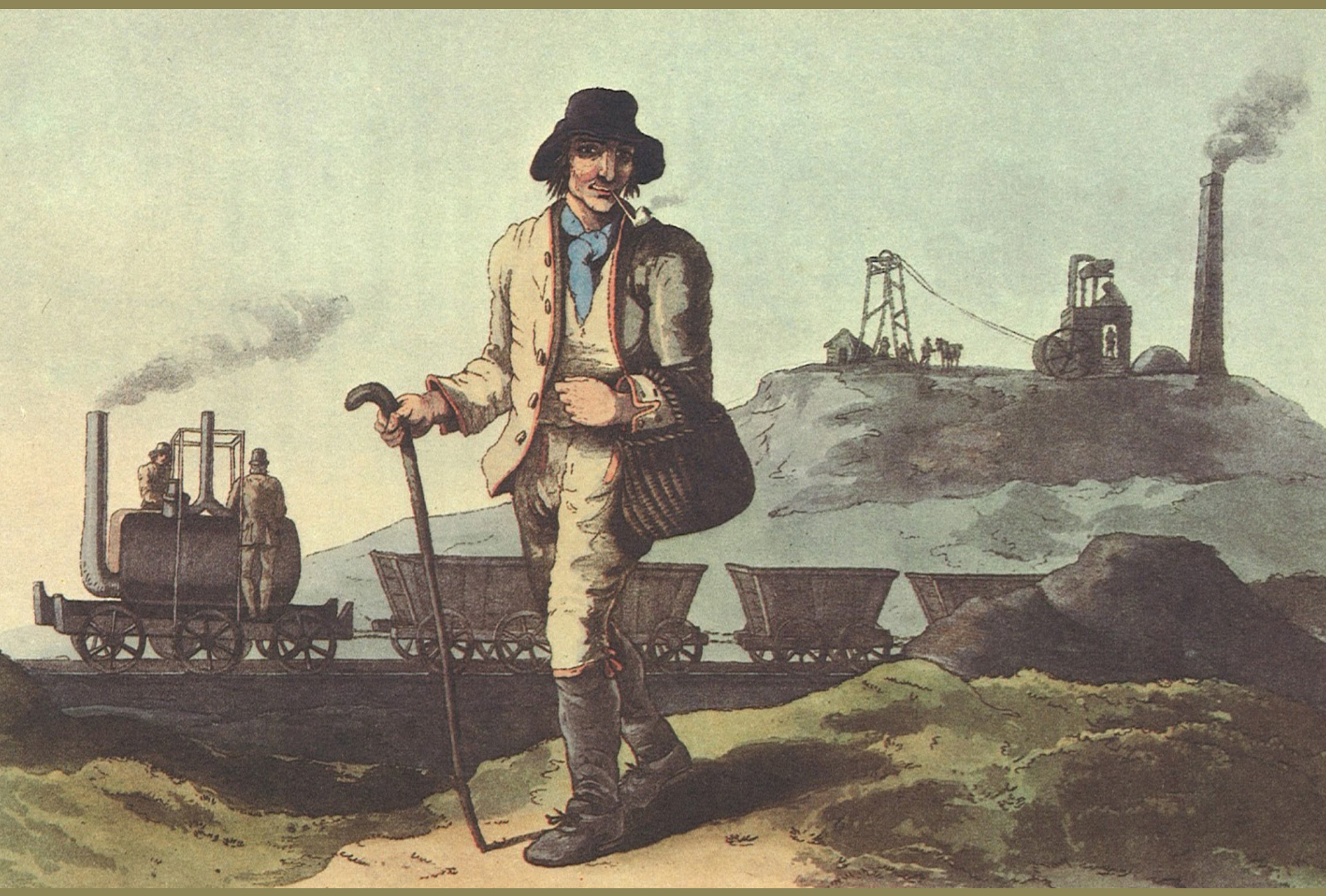




\section{FICHA TÉCNICA}

ORGANIZAÇÃO DO NÚMERO Marcelo Badaró Mattos e Vinícius de Rezende REVISÃO DE TEXTO Denize Gonzaga PROJETO GRÁFICO E DIAGRAMAÇÃO Virgínia Loureiro

COLABORARAM COM ESTE NÚMERO (consultores ad hoc)

Adhemar Lourenço da Silva Jr. (UFPEL), Alexandre Fortes (UFRRJ), Andréa Maia (UFRJ), Angela Vergara (California State University), Anicleide Zequini (Museu Paulista/USP), Antonio Luigi Negro (UFBA), Bárbara Geraldo de Castro (UNICAMP), Bruno Dornellas (UPE), Carlos Alberto de Oliveira (UESC), Carlos Zacarias F. de Sena Júnior (UFBA), Ciro Bezerra (UFAL), Cláudio Batalha (UNICAMP), Claudio Pereira Elmir (UNISINOS), Cristiana Moyano (USACH), Cristiane Muniz Thiago (UFMA), Cristina Scheibe Wolff (UFSC), Demian Melo (UFRJ), Elizabete Rodrigues da Silva (UFBA), Evangelia Aravanis (ULBRA), Fábio Henrique Lopes (UFRRJ), Fernando Teixeira da Silva (UNICAMP), Flávio Limoncic (UNIRIO), Gladyson Stélio Pereira Brito (UFPE-SEMED), Gonzalo Alvarez (CONICET), Leonardo Affonso de Miranda Pereira (PUC-Rio), Lorena Poblete (CONICET-IDES), Marcelo Badaró Mattos (UFF), Márcia C. O. de Cury (UNIJORGE), Márcia Espig (UFPEL), Marcus Dezemone (UFF e UERJ), Marcus Vinicius de Freitas Rosa (UNICAMP), Maria Camou (UDELAR), Maria Celma Borges (UFMS), Maria das Graças de Andrade Leal (IPHAN), Marina Soler Jorge (UNIFESP), Marta de Almeida (MAST/RJ), Maurício Sardá Faria (UFPB), Norberto Ferreras (UFF), Osvaldo Batista Acioly Maciel (UFAL), Paulo Fontes (CPDOC/FGV), Raphael Jonathas da Costa Lima (UFF), Ricardo Medeiros Pimenta (IBICT), Rodolfo Porrini (UDELAR), Ronaldo Pereira de Jesus (UFJF), Samuel de Souza (DIEESE), Sebastian Guevara (UBA), Sérgio Eduardo Martins Pereira (UFMA), Sheille Freitas (UNIOESTE), Silvia Regina Ferraz Petersen (UFRGS), Tiago Bernardon de Oliveira (UEPB), Victoria Basualdo (CONICET/ FLACSO), Vinícius de Rezende (UFRB), Wellington Castellucci Junior (UFRB).

Créditos da capa: The collier. Ilustração de R. D. Havell, 1813. Imagem da capa da $1^{\text {a }}$ edição de The Making of the English Working Class. 


\title{
MUNDOS DO TRABALHO
}

Publicação eletrônica semestral do GT “Mundos do Trabalho” - ANPUH

\author{
GRUPO DE TRABALHO “MUNDOS DO TRABALHO" \\ (http://gtmundosdotrabalho.org/) \\ Coordenação Nacional \\ Aldrin Castellucci \\ Coordenações Estaduais \\ Mato Grosso Do Sul \\ Vitor Wagner Neto de Oliveira \\ Rio Grande Do Sul \\ Alisson Droppa - Coordenador \\ Icaro Bittencourt - Vice-Coordenador \\ Santa Catarina \\ Adriano Luiz Duarte \\ São Paulo \\ Dainis Karepovs \\ Paraná \\ Antônio de Pádua Bosi
}

ISSN 1994-9222

http://www.periodicos.ufsc.br/index.php/

mundosdotrabalho
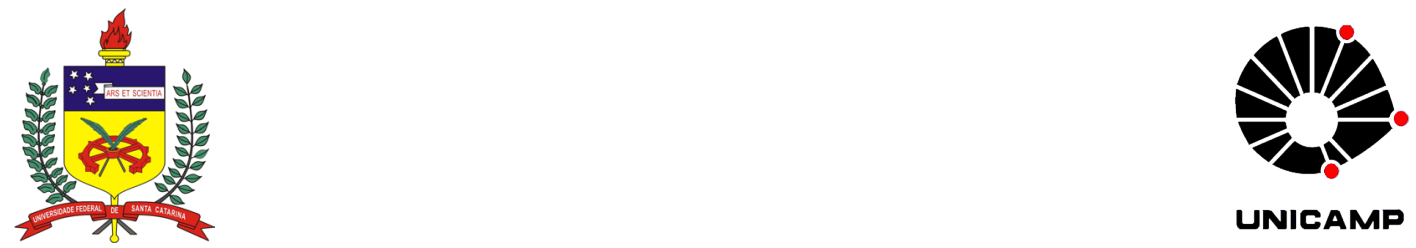

Apoio logístico

Apoio institucional

Programa de Pós-graduação em História da UNICAMP 


\section{EQUIPE EDITORIAL}

\section{EDITORES}

Clarice Speranza

Universidade Federal de Pelotas

Cristiana Schettini

Consejo Nacional de Investigaciones Científicas

y Técnicas - Universidad de Buenos Aires - Universidad de San Martín

Deivison Gonçalves Amaral

Universidade Estadual de Campinas

David Lacerda

Universidade Estadual de Campinas

Fabiane Popinigis

Universidade Federal Rural do Rio de Janeiro

Isabel Aparecida Bilhão

Universidade do Vale do Rio dos Sinos

Henrique Espada

Universidade Federal de Santa Catarina

Larissa Correa

Correspondente do Instituto Internacional de História Social de Amsterdam no Brasil

Marcelo Mac Cord

Universidade Federal Fluminense

Osvaldo Batista Acioly Maciel

Universidade Federal de Alagoas

Paulo Cruz Terra

Universidade Federal Fluminense

Vinícius de Rezende

Universidade Federal do Recôncavo da Bahia

\section{CONSELHO EDITORIAL}

Alexandre Fortes

Universidade Federal Rural do Rio de Janeiro, Brasil

Antonio Luigi Negro

Universidade Federal da Bahia, Brasil

Barbara Weinstein

New York University, Estados Unidos

Beatriz Ana Loner

Universidade Federal de Pelotas, Brasil

Beatriz Mamigonian

Universidade Federal de Santa Catarina, Brasil
Cláudio Henrique de Moraes Batalha

Universidade Estadual de Campinas, Brasil

Dick Geary

Nottingham University, Grã-Bretanha

Flavio dos Santos Gomes

Universidade Federal do Rio de Janeiro, Brasil

John D. French

Duke Universtiy, Estados Unidos

José Ricardo G. P. Ramalho

Universidade Federal do Rio de Janeiro, Brasil

José Sérgio Leite Lopes

Museu Nacional - Universidade Federal do Rio de Janeiro, Brasil

Juan Suriano

Universidad de Buenos Aires, Argentina

Marcel Van Der Linden

International Institute of Social History, Holanda Marcelo Badaró Mattos

Universidade Federal Fluminense, Brasil

Marco Aurélio Santana

Universidade Federal do Rio de Janeiro, Brasil

Maria Célia P. M. Paoli

Universidade de São Paulo, Brasil

Michael Mcdonald Hall

Universidade Estadual de Campinas, Brasil

Michel Ralle

Université de Paris IV (Sorbonne), Paris

Mirta Zaida Lobato

Universidad de Buenos Aires, Argentina

Norberto Osvaldo Ferreras

Universidade Federal Fluminense, Brasil

Prabhu Mohapatra

University of Delhi, Índia

Sidney Chalhoub

Universidade Estadual de Campinas, Brasil

Vitor Wagner Neto de Oliveira

Universidade Federal do Mato Grosso do Sul, Brasil

\section{GERENTES}

Henrique Espada Lima

Fabiane Popinigis 


\section{Apresentação}

\section{Marcelo Badaró Mattos* Vinícius de Rezende**}

Em 2013, dezenas de eventos acadêmicos e publicações ao redor do mundo registraram os 50 anos da publicação do livro $A$ formação da classe operária inglesa e os 20 anos da morte de seu autor, o historiador inglês Edward Palmer Thompson. Homenagens que revelaram a amplitude verdadeiramente global da repercussão da obra thompsoniana. Algo que não deixa de ser curioso, visto que uma das características mais marcantes do seu trabalho como historiador tenha sido sua preocupação com o estudo das particularidades de cada contexto histórico, o que o fez circunscrever suas obras de análise histórica ao estudo de uma formação social específica e "peculiar", a Inglesa. Por certo que a história da Inglaterra, primeira grande potência imperialista do mundo capitalista industrial, afetava e era afetada pela presença global do Império Britânico, o que poderia explicar porque a história das lutas sociais na Inglaterra dos séculos XVIII e XIX, estudadas por Thompson, interessaram a tanta gente. Além disso, como aquela foi a primeira sociedade a experimentar a formação de uma classe trabalhadora assalariada em sua forma contemporânea, talvez muitos dos leitores de Thompson levassem a sério a proposta internacionalista, explicitamente comprometida com o presente e o futuro, que ele apresentou no prefácio de A formação, quando escreveu que "causas que foram perdidas na Inglaterra poderiam ser ganhas na África e na Ásia”. ${ }^{\prime}$

Talvez tenha sido ainda mais decisiva a importância que sua obra teve como referência teórica e metodológica para historiadores que concordaram com os pressupostos do que Thompson definiu como a "lógica da história", entendida como "um diálogo entre conceito e evidência, um diálogo conduzido por hipóteses sucessivas, de um lado, e a pesquisa empírica, do outro".2

Qualquer que seja a razão, e provavelmente uma combinação desses e de outros elementos seja necessária para explicar melhor a questão, o fato é que, entre as influências decisivas para a renovação dos estudos de História Social do Trabalho no Brasil, como bem acentuou Claudio Batalha, "um papel primordial coube à historiografia marxista inglesa, particularmente A formação da classe operária inglesa, de Edward Thompson". ${ }^{3}$

* Professor titular de História do Brasil da UFF e bolsista de Produtividade do CNPq.

** Doutor em História Social do Trabalho pela UNICAMP e professor de História Contemporânea da UFRB.

1 Essa sugestão é feita por HAMILTON, Scott. The crisis of theory: E. P. Thompson, the New Left and postwar Britsh politics. Manchester: Manchester University Press, 2011, p. 123.

2 THOMPSON, E. P. A miséria da teoria, ou um planetário de erros: uma crítica ao pensamento de Althusser. Rio de Janeiro: Zahar, 1981, p. 49.

3 BATALHA, Claudio H. M. "A Historiografia da classe operária no Brasil: trajetória e tendências". In: FREITAS, Marcos C. de. Historiografia brasileira em perspectiva. São Paulo: Contexto, 2001, p. 152. 
Por isso mesmo, Mundos do Trabalho, uma revista que procura refletir a produção da historiografia do trabalho no Brasil e suas relações internacionais, não poderia deixar de também homenagear a obra e valorizar o legado de E. P. Thompson. É esse o sentido geral do dossiê temático que ora apresentamos aos nossos leitores e leitoras.

O presente dossiê é composto por quatro artigos, escritos por historiadores e sociólogos brasileiros e estrangeiros, dedicados a refletir sobre as principais características de A formação; as apropriações e interpretações da obra thompsoniana; a repercussão de seus textos em variados contextos históricos e em diferentes localidades; e a relação entre as formulações e interpretações de Thompson e as construções teóricas de outros escritores vinculados à tradição marxista.

Para abrir nossa homenagem a E. P. Thompson, elegemos o artigo do historiador canadense Bryan D. Palmer. Nada mais adequado, pois Palmer se dedica a interpretar as principais características dos três volumes de $A$ formação da classe operária inglesa a partir da perspectiva de que a obra foi formulada tendo como principal fio condutor as polêmicas e os debates em que Thompson se envolveu durante sua elaboração.

Uma das principais contribuições do artigo de Bryan Palmer é destacar a importância decisiva da experiência de Thompson enquanto educador de adultos para a formulação de A formação, visto que o livro foi escrito para os trabalhadores, sindicalistas e militantes com os quais o autor trabalhou ao longo de anos. Segundo Palmer, na condição de tutor de adultos, Thompson não possuía uma posição romântica e passiva frente à classe trabalhadora; ao contrário, ele visava contribuir para promover o nível de consciência dos trabalhadores e formar socialistas e revolucionários. Tal postura se refletiu diretamente na maneira como as tradições e experiências da classe operária inglesa foram interpretadas de forma crítica em seu livro. Além disso, a própria estruturação de $A$ formação teria resultado do fato de Thompson almejar entrar em contato com a cultura autodidata de seus alunos, com as experiências intelectual e política com as quais ele se deparava no trabalho de extensão.

Bryan Palmer demonstra que Thompson combateu em todas as frentes e analisou de maneira dialética os variados temas que compuseram sua interpretação do processo de formação da classe operária inglesa: o radicalismo popular; a complexa contribuição da religião; a importância das "classes perigosas"; a disciplina capitalista; o constitucionalismo; a conspiração oculta e as tradições insurrecionais; as manifestações da turba; o luddismo; entre outros. Thompson polemizou com as diferentes ortodoxias e, inclusive, com muitas das concepções arraigadas de seus alunos, como a visão negativa para com os trabalhadores que no início da revolução industrial recusavam a autodisciplina; ou a ideia de que a classe operária inglesa teria se formado tendo apenas o trabalhismo e a moderação como componentes. De tal maneira, Palmer sustenta que é extremamente infrutífero tentar rotular E. P. Thompson e sua obra em definições estáticas, uma vez que, assim como sua concepção de classe, ele era um escritor relacional.

O segundo texto do dossiê foi elaborado pela historiadora Mirta Zaida Lobato, que, a partir de suas próprias experiências enquanto estudante e, posteriormente, como pesquisadora e professora, reflete sobre a apropriação e difusão de A formação da classe operária inglesa na Argentina, no transcorrer das últimas décadas. Como destaca Lobato, tal reflexão adquire significativa importância porque os modos de ler são construções históricas em constante transformação, visto que 
por meio da recepção de determinados textos são criadas pontes entre comunidades intelectuais diferentes, pois as ideias viajam e ao serem traduzidas se mesclam com leituras locais e adquirem características próprias.

A partir dessa compreensão, Lobato afirma que no começo dos anos de 1970 o historiador inglês era desconhecido no meio universitário argentino, marcado pela falta de estímulo aos debates e diálogos com outras disciplinas, por um pequeno número de professores dedicados ao estudo da História Social ou do Trabalho e pela subordinação dos interesses de pesquisa à política nacional. Sob tais circunstâncias, seu primeiro contato com textos relacionados aos mundos do trabalho se deu fora do sistema universitário oficial, por meio dos grupos de estudos. Neste espaço de aprendizado e reflexão coletiva, os participantes liam e debatiam os livros escritos por dirigentes sindicais e, por meio destes, pela primeira vez Lobato teve contato com o nome de E. P. Thompson e de seu livro. Com o golpe militar na Argentina, muitos estudantes deixaram o ensino universitário e os grupos de estudos extrauniversitários continuaram a se constituir no ambiente privilegiado para as reflexões no campo da História Social, especialmente, por meio da leitura de $A$ formação e das obras de Eric Hobsbawm. A historiadora destaca ainda que esses grupos de estudos tornaram possível aos seus membros superar o provincianismo e se abrir ao contato com os pesquisadores britânicos, franceses e latino-americanos no pós-ditadura.

Após o fim da ditadura, Lobato intensificou seu estudo da obra de Thompson e de vários outros autores da História Social, motivada pela experiência como pesquisadora de uma comunidade operária - Berisso - e pelo início da carreira docente. Nos anos de 1980, a leitura de Thompson foi fundamental para se estudar os mundos do trabalho, pois ajudava a romper com as fronteiras da disciplina, gerava novas sensibilidades, e problematizava o marxismo, com seu conceito de classe e com a valorização dada aos significados atribuídos pelos próprios trabalhadores às suas ações. Em meio às transformações da sociedade argentina pós-ditadura, várias frentes de pesquisa se abriram e nem todas privilegiaram a classe trabalhadora. Entre aqueles que se dedicaram ao estudo das experiências dos trabalhadores, os interesses de pesquisa também foram diversos e várias temáticas foram desenvolvidas para além do movimento operário fabril, por exemplo, com a difusão dos estudos de gênero, raça e etnia.

Dessa maneira, podemos concluir que uma das principais contribuições do texto de Mirta Lobato é demonstrar como a difusão da obra de um autor em outro país está diretamente relacionada à conjuntura política e institucional do receptor. Assim, a leitura de Thompson na Argentina se relacionou às recepções, às traduções, às políticas editoriais, aos processos políticos, institucionais e disciplinares ao longo do tempo. Do mesmo modo, a própria interpretação da obra thompsoniana transformou-se em função dos interesses de pesquisa de seus leitores.

No terceiro texto do dossiê, os sociólogos Giovanni Alves e Renan Araujo aproximam as obras de E. P. Thompson e de Georg Lukács com o objetivo de resgatar os "fundamentos ontológicos" do conceito de experiência tal como utilizado por Thompson. Segundo os autores, uma apreensão correta desse conceito, na perspectiva de uma "ontologia do ser social”, pode contribuir efetivamente para a resolução da polêmica marxista da relação entre estrutura e sujeito ou entre base e superestrutura.

Alves e Araujo consideram que, ao criticar o reducionismo e as interpretações deterministas da problemática base e superestrutura, Thompson foi equivocadamente acusado de desprezar a especificidade da produção como determinação 
principal, dissolvendo, desse modo, a materialidade. De maneira distinta, eles consideram que Thompson buscou, e com sucesso, compreender na sua totalidade concreta a condição de "proletariedade" de homens e mulheres. Para tanto, por meio da categoria de experiência, ele recuperou na pesquisa histórica a mais fina articulação dialética entre liberdade e necessidade. Ao diferenciar a experiência vivida e a experiência percebida, Thompson se contrapôs ao althuserianismo, que considera a experiência como exclusivamente ideológica. Assim, a experiência seria um conceito mediador entre o ser social e a consciência social. Não obstante, como Thompson não elaborou categorialmente uma ontologia do ser social, ele não teria conseguido expressar com desenvoltura, em termos lógico-dialéticos, a metodologia de Marx.

Destarte, torna-se relevante aproximar Thompson e Lukács, pois o último buscou instaurar as bases epistemológicas para o conhecimento do ser social naquilo que ele tem de "fundante" e de "estruturante". Para Lukács, a categoria trabalho é "fundante" do ser social, é o modelo da práxis social capaz de articular as categorias de liberdade e necessidade, constituindo-se na base fundamental da explicação dialético-materialista da relação entre estrutura e sujeito. Assim, Alves e Araujo concluem que a categoria trabalho constitui-se na matriz ontológica da experiência histórica que Thompson buscou resgatar no sentido dialético.

Autores como E. P. Thompson, Georg Lukács e Antonio Gramsci fariam parte dos marxistas humanistas que se opuseram ao estruturalismo, por possuírem uma visão de totalidade e de não determinação do econômico, como fazem os althusserianos. Por isso, o diálogo da obra de Thompson com a "ontologia do ser social" de Lukács contribuiria para dar um "estatuto ontológico" ao conceito de experiência de Thompson, evitando a utilização inadequada de sua obra por parte dos pós-modernistas, que tendem a incluí-lo entre os "culturalistas".

Encerrando o dossiê, temos o texto do historiador Juan Grigera, que realiza um balanço dos estudos recentes sobre as transformações produtivas, em especial a desindustrialização, e as formas de conflito social na Argentina pós-ditadura. Para tanto, Grigera parte da concepção de que o núcleo central da obra de Thompson é refletir sobre a articulação entre as formas de luta de classes e as transformações dos modos de acumulação do capital, procurando, então, verificar se tal perspectiva foi apreendida pelos pesquisadores dedicados à História do Trabalho na Argentina.

Após sintetizar as principais interpretações a respeito da relação entre as transformações na estrutura produtiva e o movimento operário; das transformações do partido peronista nas décadas de 1980 e 1990; e das características dos protestos sociais contemporâneos, Grigera conclui que haveria uma desarticulação entre os estudos sobre os conflitos sociais e os estudos a respeito das transformações dos modos de acumulação do capital. Segundo o autor, predomina um silêncio a respeito da relação entre conflito social e luta de classes e as transformações da estrutura econômica, processos de industrialização e padrões de acumulação. Por isso, Grigera afirma a necessidade de se retomar a obra de E. P. Thompson, já que sua reflexão a respeito da relação entre industrialização, classe e luta de classes seria uma das mais criativas na tradição marxista.

Juan Grigera afirma que desde as primeiras obras de Karl Marx e de Friedrich Engels a formação da classe trabalhadora foi compreendida como possuindo dois momentos: a relação fundamental entre as classes em torno da exploração e da resistência, e a constituição das classes em sua dimensão política. Alguns autores da tradição marxista definiram esses dois momentos como a "classe em si" e a 
“classe para si". Thompson teria se dedicado justamente a interpretar a complexa relação entre os dois momentos, utilizando o conceito de experiência para articulálos, buscando sistematizar as formas de articulação das respostas culturais, sociais e coletivas à exploração. Tal compreensão da interpretação thompsoniana contribuiria para se superar os limites da historiografia recente na Argentina que, segundo Grigera, se devem à conjuntura em que se deu a recepção de Thompson no país, uma vez que nos anos de 1980, os autores estavam afastados do ativismo político, do marxismo e crescentemente comprometidos com a construção da ordem democrática.

Além dos quatro artigos do dossiê E. P. Thompson, a décima edição de Mundos do Trabalho traz a público oito artigos e quatro resenhas de autores de variadas instituições brasileiras e de uma instituição argentina. Tais contribuições demonstram como o campo da História Social tem produzido análises de qualidade em grande escala, dedicadas a compreender os conflitos sociais de forma ampla; as articulações entre o público e o privado; as relações e os conflitos entre as classes sociais e o Estado; as apropriações, interpretações e disputas em torno das leis; as características do movimento operário; as especificidades regionais e nacionais; os impactos das transformações dos processos produtivos e do contexto político sobre categorias profissionais específicas; as formas de organização e de mobilização e formação de laços de solidariedade; entre outras temáticas. Em comum, a maior parte dos autores desenvolveu pesquisas direta ou indiretamente influenciadas pelas interpretações e perspectivas analíticas de E. P. Thompson.

Como o leitor poderá observar por meio dos quatro artigos que compõem o dossiê e dos demais textos que abrilhantam essa edição, assim como E. P. Thompson não se prendeu às ortodoxias, sua obra possibilita diferentes apropriações e interpretações, em grande medida relacionadas aos contextos históricos em que se dá sua recepção e também aos posicionamentos teóricos e políticos de seus leitores. Nesse sentido, após 50 anos da publicação de A formação da classe operária inglesa, este e os outros livros de Thompson continuam a inspirar um rico debate decorrente das diferentes interpretações que possibilitam. Como o conjunto de textos aqui demonstra, a obra thompsoniana não se tornou nova fonte de ortodoxia, mesmo porque seu autor não tinha a pretensão de formular axiomas dentro de uma ortodoxia marxista.

Assim, esperamos que essa homenagem prestada a E. P. Thompson pela Mundos do Trabalho se constitua em fonte de inspiração para que seus livros continuem a ser lidos, debatidos e interpretados, para que sua obra permaneça como peça fundamental para a formação das futuras gerações de historiadoras e historiadores dedicados a estudar o processo de formação das classes sociais como um acontecimento histórico, relacional e dialético, que deve ser analisado por meio da constante confrontação crítica entre teoria e análise empírica. 